\title{
Erratum to: Utilization of Licensed Shared Access Resources in Indoor Small Cells Scenarios
}

\author{
Eva Perez ${ }^{1(\bowtie)}$, Karl-Josef Friederichs ${ }^{1}$, Andreas Lobinger ${ }^{1}$, \\ Bernhard Wegmann ${ }^{1}$, and Ingo Viering ${ }^{2}$ \\ ${ }^{1}$ Bell Labs Research, Nokia, Munich, Germany \\ \{eva. perez, karl-josef. friederichs, andreas. lobinger, \\ bernhard.wegmann\}@nokia.com \\ ${ }^{2}$ Nomor Research, Munich, Germany \\ viering@nomor.de
}

\section{Erratum to:}

Chapter 38: D. Noguet et al. (Eds.)

Cognitive Radio Oriented Wireless Networks

DOI: 10.1007/978-3-319-40352-6_38

The title of the paper starting on page 462 was incomplete and should read:

"Utilization of Licensed Shared Access Resources in Indoor Small Cells Scenarios" This has been corrected.

The updated original online version for this Chapter can be found at 10.1007/978-3-319-40352-6_38 